\title{
FINITE-ELEMENT MODELLING OF STRESS-STRAIN STATE IN WELDABILITY TESTS (PVR-TEST)
}

\author{
K.A. YUSHCHENKO, E.A. VELIKOIVANENKO, N.O. CHERVYAKOV, \\ G.F. ROZYNKA and N.I. PIVTORAK \\ E.O. Paton Electric Welding Institute, NASU \\ 11 Kazimir Malevich Str., 03680, Kiev, Ukraine. E-mail: office@paton.kiev.ua
}

\begin{abstract}
Hot cracks appearing in process of welding are an important problem determining weldability of number of structural materials. Regardless the fact that this phenomenon is widely investigated in course of many decades a nature of hot crack appearance is still a relevant problem for number of current alloys in fusion welding. To reach wider understanding of a mechanism of hot crack formation a finite-element method was used for mathematical modelling of PVR-Test. Realizing the mathematical model employing the experimental data, received as a result of such testing, allowed getting stress and strain distribution in the crack formation zones. The zones of plastic strain positive increments, promoting crack formation, were found for a range of brittleness temperature interval. Prediction of the zones of higher susceptibility to hot crack appearance as a result of decrease of material ductility well agrees with the experimental investigations. 8 Ref., 1 Table, 4 Figures.
\end{abstract}

Keywords : hot cracks, weldability testing, welding, PVR-Test, nickel alloys, finite-element method

High-alloy steels and nickel alloys are one of the most essential structural materials capable to withstand extreme temperatures and power loads as well as resist effect of aggressive media. They are mostly used in chemical, oil and power machine building and other branches of industry for manufacture of structures operating in a wide temperature range. Overwhelming majority of the high-alloy steels and nickel alloys refer to a structural class of austenite structural materials, characterized with structure stability in a wide range of operating temperatures, high temperature resistance, heat resistance and resistance to aggressive media effect.

Most stably austenite materials have high sensitivity to hot crack formation in fusion welding. The main difficulties in welding of considered materials are caused by their multi-component alloying and variety of operating conditions of the welded structures. The primary and general peculiarity of these materials is susceptibility to formation of hot cracks, having intergranular nature [1], in the weld and near-weld zone. Susceptibility to crack formation is evaluated with the help of current methods for weldability evaluation Varestraint-Test and PVR-Test [2-4].

The PVR-Test method is recommended by the International Institute of Welding for evaluation of weldability of structural materials in single-pass and multi-pass welding, first of all of the materials with stably austenite structure, sufficiently sensitive to crack formation.
Principle of the PVR-Test is based on the grounds of theory of process strength developed by N.N. Prokhorov [5]. The method of crack resistance evaluation is realized by means of non-consumable welding without filler along a central plane axis with simultaneous longitudinal varying in time sample deformation.

A crack formation sensitivity criterion is a critical deformation rate $v_{\mathrm{cr}}$, at which first cracks appear. Simultaneous appearance of the cracks in a weld as well as heat affected zone is possible in welding. Moreover, these cracks appear, as a rule, at different value of critical deformation rate $v_{\text {cr }}$. This allows for having quantitative description of sensitivity to a specific type of cracks. More accurate information on a moment of crack formation start can be received through examination of a weld surface using optical enlargement methods.

An aim of the work was mathematical modelling of a weldability testing method (PVR-Test) for more complete analysis of the peculiarities of stresses and deformations localizing as well as determination of possible zones of crack formation.

Carried investigation was made applicable to alloy of $\mathrm{Ni}-\mathrm{Cr}-\mathrm{Fe}$ alloying system which is widely used in nuclear power engineering.

The experimental data, received at forced deformation for evaluation of crack formation susceptibility [6], were used for development of a PVR-Test mathematical model using finite-element method [7]. This allowed computing temperature, stress and de- 
formation fields for different zones of a welded joint at macrolevel.

A computational procedure [8] was used for evaluation of kinetics of stress-strain state of the sample. It is based on sequential tracing of a development of elasto-plastic deformations in $x, y$ points of considered sample at temperature change during source movement.

A hypothesis of two-dimensional stress state was used. According to it a stress tensor $\sigma_{i j}$ in any point $x$, $y$ in a moment of time $t$ is presented as following

$$
\sigma_{i j}=\left\|\begin{array}{cc}
\sigma_{x x} & \sigma_{x y} \\
\sigma_{y x} & \sigma_{y y}
\end{array}\right\|,\left(\sigma_{y x}=\sigma_{x y}\right),
$$

where the tensor components $\sigma_{i j}$ in each point $x, y$ of considered area satisfy the equilibrium equations

$$
\frac{\partial \sigma_{x x}}{\partial x}+\frac{\partial \sigma_{x y}}{\partial y}=0, \frac{\partial \sigma_{x y}}{\partial x}+\frac{\partial \sigma_{y y}}{\partial y}=0 .
$$

Deformation tensor $\varepsilon_{i j}$ has structure similar to $\sigma_{i j}$ tensor, i.e.

$$
\varepsilon_{i j}=\left\|\begin{array}{cc}
\varepsilon_{x x} & \varepsilon_{x y} \\
\varepsilon_{y x} & \varepsilon_{y y}
\end{array}\right\|,\left(\varepsilon_{x y}=\varepsilon_{y x}\right),
$$

where components $\varepsilon_{x x}, \varepsilon_{x y}, \varepsilon_{y y}$ are related with $U_{x}$ and $U_{y}$ movements by relationships

$$
\begin{aligned}
& \varepsilon_{x x}=\frac{\partial}{\partial x}, \varepsilon_{y y}=\frac{\partial}{\partial y}, \\
& \varepsilon_{x y}=-\left(\frac{\partial}{\partial y}+\frac{\partial}{\partial x}\right)
\end{aligned}
$$

In a random moment of time $t$ tensor $\varepsilon_{i j}$ can be presented as a sum of tensors [1]

$$
\varepsilon_{i j}=\varepsilon_{i j}^{e}+\varepsilon_{i j}^{p}+\varepsilon_{i j}^{c},
$$

where $\varepsilon_{i j}^{\mathrm{e}}$ is the tensor of elastic deformation; $\varepsilon_{i j}^{\mathrm{p}}$ is the tensor of non-elastic deformation of instantaneous ductility; $\varepsilon_{i j}^{\mathrm{c}}$ is the tensor of non-elastic creep deformation.

Relationship between tensor $\sigma_{i}$ and tensor $\varepsilon_{i j}^{\mathrm{e}}$ is determined by Hooke's law, i.e. there are following dependencies taking into account temperature and microstructure changes $3 \varphi$ in point $x, y$ in a moment of time $t$ in comparison with $t=0$ has

$$
\begin{gathered}
\varepsilon_{i j}^{\mathrm{e}}=\frac{\sigma_{i j}-\delta_{i j} \sigma}{2 G}+\delta_{i j}[K \sigma+\varphi(t)-\varphi(0)], \\
(i, j=x, y),
\end{gathered}
$$

where $\delta_{i j}$ is the single tensor or Kronecker symbol, i.e. $\delta_{i j}=1$ at $i=j$ and $\delta_{i j}=0$ at $i \neq j ; \sigma=\left(\sigma_{x x}+\left(\sigma_{y y}\right) / 3, G=\right.$ $=E /(2(1+v))$ is the shear modulus; $E$ is the normal elasticity modulus; $v$ is the Poisson's ratio; $K=(1-$ $2 v) / E$ is the volumetric compression modulus.

Relationship of stress tensor $\sigma_{i}$ with instantaneous ductility deformations $\varepsilon_{i j}^{\mathrm{p}}$ in current commercial packages of computer software such as «Weldpredictions» is enunciated based on flow theory, associated with
Mises yield criterion. i.e. relationship is registered between a tensor of plastic deformation increments $\Delta \varepsilon_{i j}^{\mathrm{p}}$ and stress deviator $\sigma_{i j}-\delta_{i j} \sigma$ in form of

$$
\Delta \varepsilon_{i j}^{\mathrm{p}}=d \lambda\left(\sigma_{i j}-\delta_{i j} \sigma\right), \quad(i, j=x, y),
$$

where a scalar function $d \lambda$ is determined by yield condition through yield surface

$$
f=\sigma_{i}^{2}-\sigma_{0.2}^{2}(T),
$$

where

$$
\sigma_{i}=\frac{1}{2} \sqrt{\left(\sigma_{x x}-\sigma_{y y}\right)^{2}+\sigma_{x x}^{2}+\sigma_{y y}^{2}+6 \sigma_{x y}^{2}},
$$

$\sigma_{0.2}(T)$ is the material yield in $x, y$ point at temperature $T(t)$.

$$
\begin{gathered}
d \lambda=0, \text { if } f<0 \text { or } f=0, \text { but } d f<0 ; \\
d \lambda>0, \text { if } f=0 \text { and } d f>0 ; \\
\text { state } f>0 \text { is inadmissible. }
\end{gathered}
$$

Tracing of the development of elastic-plastic deformations is carried out step-by-step, stating from moment $t=0$ through time gap $\Delta \tau$, the same as tracing of the development of temperature field $T(x, y, t)$ in time is carried out in series through finite increments of time $\Delta t$.

Deformation tensor will acquire final increment during this tracing step.

$$
\Delta \varepsilon_{i j}=\Delta \varepsilon_{i j}^{\mathrm{e}}+\Delta \varepsilon_{i j}^{\mathrm{p}}
$$

or taking into account (6), (7)

$$
\Delta \varepsilon_{i j}=\psi\left(\sigma_{i j}-\delta_{i j} \sigma\right)+\delta_{i j} K \sigma-b_{i j},
$$

where

$$
\begin{gathered}
\psi=\frac{1}{2 G}+\Delta \lambda, \\
b_{i j}=\left(\frac{\sigma_{i j}-\delta_{i j} \sigma}{2 G}\right)_{t-\Delta \tau}+\delta_{i j}\left[\left(K \sigma_{t-\Delta \tau}-\Delta \varphi\right)\right] .
\end{gathered}
$$

Function $\psi$ reflects a state of the material in point $x, y$ in time moment $t$. It equals $1 / 2 G$ (elastic behavior) or more than $1 / 2 G$ elastic-plastic behavior. Yield condition (8) allows for developing $\psi$ function iterative refinement. Value $b_{i j}$ is known for tracing stage (time moment $t)$, if solution at stage $(t-\Delta \tau)$ is known.

Dependence (12) at each iteration on $\psi$, i.e. when $\psi$ is set, converts considered problem to a well known problem of thermoelasticity theory with additionally set deformations $b_{i j}$. Numerical methods based on finite-element method [8] are sufficiently well developed for such problems' solution. Such an algorithm type is used in software package «Weldpredictions». It made a basis for investigation of residual deformations depending on applied load as well as heat input (or welding mode).

Figure 1 shows the model for macrolevel (sample and scheme of its loading). The sample was divided on 8 sections, within the limits of which the deformation rate was constant. Kinetics of stress-strain state in the weld and heat-affect zone (HAZ) was calculated 


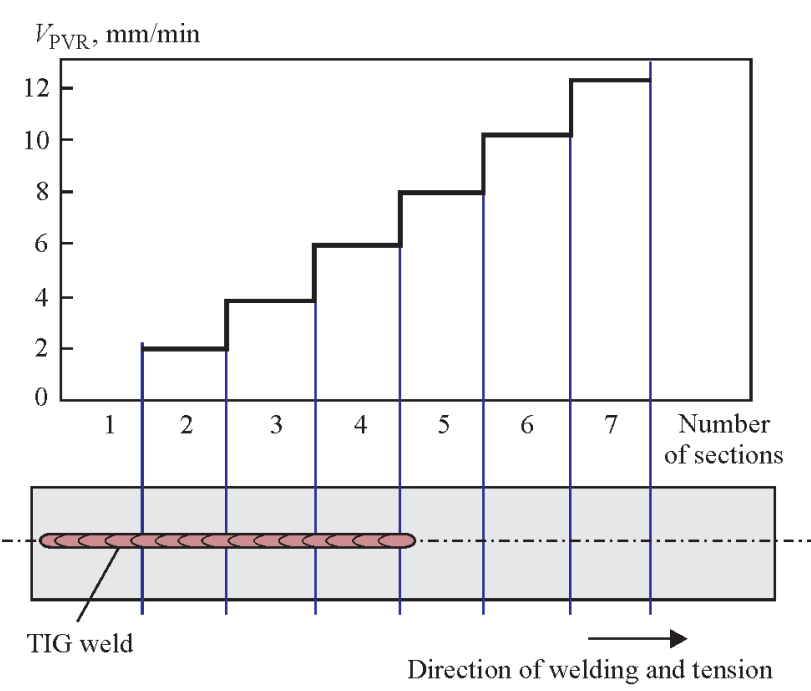

Figure 1. Sample and scheme of its loading

for each of sections (2-8) for macrolevel at $0.5 \mathrm{~mm}$ distance from fusion line in the places of appearance of ductility dip cracks under real testing conditions.

The model considers all heat and mechanical effects in the process of real PVR-Test of the welds produced with $\mathrm{Ni}-\mathrm{Cr}-\mathrm{Fe}$ wire depending on time. Physical properties of material, depending on temperature (Table), parameters of welding mode $\left(I_{\mathrm{w}}=60 \mathrm{~A}, U_{\mathrm{a}}=\right.$ $=10.5 \mathrm{~V}, v_{\mathrm{w}}=6.5 \mathrm{~m} / \mathrm{h}$ ) and nature of mechanical loading and change of sample geometry were used. The process of testing was modeled for plane sample of $200 \times 40 \times 3 \mathrm{~mm}$ size. Size of finite element in calculations made $0.5 \times 0.5 \times 0.5 \mathrm{~mm}$.

Comparative kinetics of change of temperature, stresses and deformations in HAZ for sections 2 and 4 is shown in Figures 2 and 3.

Tension plastic deformations rise in the weld and heat affected zone in heating stage at simultaneous tension of the sample. Plastic deformations reduce to zero when reaching the temperature maximum in the weld, further decrease of temperature provokes their re-increase. Somewhat another pattern is for HAZ.

Dependence of mechanical and thermo-physical properties on temperature for examined material

\begin{tabular}{|c|c|c|c|c|c|}
\hline$T,{ }^{\circ} \mathrm{C}$ & $\begin{array}{c}E \cdot 10^{-5}, \\
\mathrm{MPa}\end{array}$ & $\sigma_{\mathrm{y}}, \mathrm{MPa}$ & $\begin{array}{c}\alpha \cdot 10^{6}, \\
1 /{ }^{\circ} \mathrm{C}\end{array}$ & $\begin{array}{c}\lambda, \\
\mathrm{J} /\left(\mathrm{cm} \cdot \mathrm{s}^{\circ}{ }^{\circ} \mathrm{C}\right)\end{array}$ & $\begin{array}{c}c \gamma, \\
\mathrm{J} /\left(\mathrm{cm}^{3}{ }^{\circ} \mathrm{C}\right)\end{array}$ \\
\hline 20 & 2.06 & 350 & 14.1 & 0.120 & 0.450 \\
\hline 100 & 2.03 & 280 & 14.1 & 0.135 & 0.470 \\
\hline 200 & 1.95 & 250 & 14.3 & 0.154 & 0.500 \\
\hline 300 & 1.87 & 240 & 14.5 & 0.173 & 0.530 \\
\hline 400 & 1.85 & 230 & 14.8 & 0.191 & 0.550 \\
\hline 500 & 1.77 & 225 & 15.2 & 0.210 & 0.580 \\
\hline 600 & 1.67 & 215 & 15.7 & 0.229 & 0.600 \\
\hline 700 & 1.58 & 200 & 16.2 & 0.248 & 0.630 \\
\hline 800 & 1.52 & 190 & 16.6 & 0.266 & 0.660 \\
\hline 900 & 1.45 & 175 & 17.0 & 0.285 & 0.680 \\
\hline 1000 & 1.35 & 150 & 17.4 & 0.301 & 0.710 \\
\hline 1100 & 1.25 & 125 & 17.8 & 0.316 & 0.740 \\
\hline 1200 & 1.0 & 100 & 18.0 & 0.330 & 0.770 \\
\hline
\end{tabular}

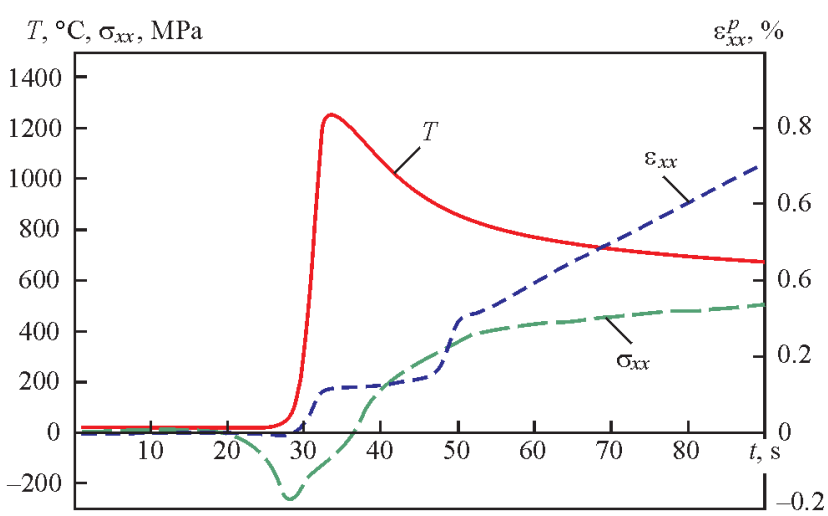

Figure 2. Kinetics of change of temperature, stresses and deformations in section 2

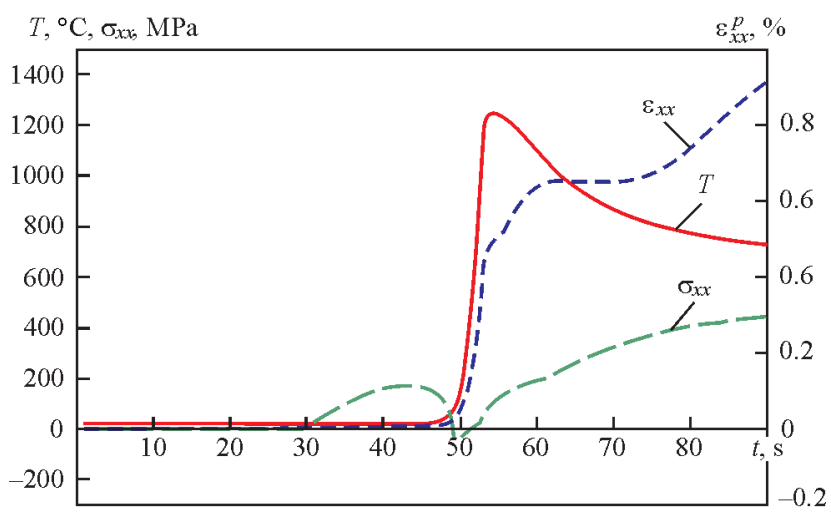

Figure 3. Kinetics of change of temperature, stresses and deformations in section 4

Since there is no metal melting in the HAZ, plastic deformations grow continuously. Rate of plastic deformation at tension rate $2 \mathrm{~mm} / \mathrm{min}$ in section 2 during cooling makes $0.00119 \% /{ }^{\circ} \mathrm{C}$ that is significantly lower than plastic deformation rate $\left(0.00539 \% /{ }^{\circ} \mathrm{C}\right)$ in section 4 at tension rate $4 \mathrm{~mm} / \mathrm{min}$. This determines higher susceptibility of material to crack formation in this section. Figure 4 shows kinetics of change of longitudinal plastic deformations in sections 2 and 4 as well as boundaries of brittleness temperature interval BTI 2.

Obtained results well agree with the experimental researches of crack resistance using PVR-Test method, when formation of ductility dip cracks under real

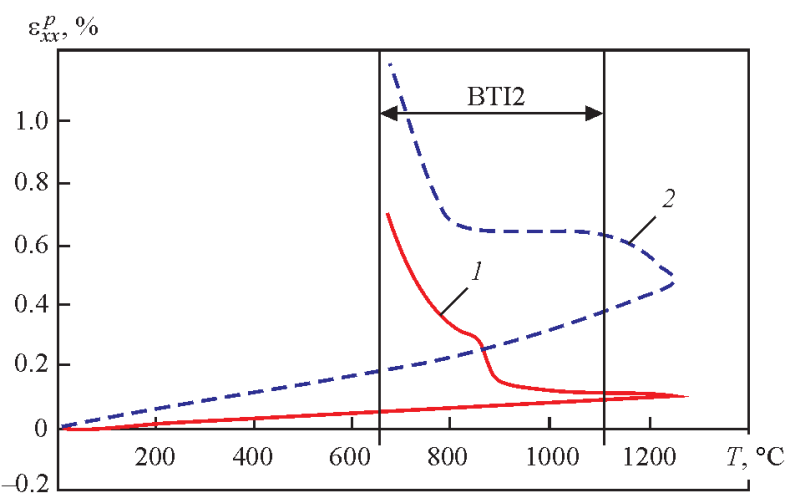

Figure 4. Kinetics of change of longitudinal plastic deformations on temperature in sections 2 (1) and 4 (2) 
tests took place at forced tension rate of more than $3 \mathrm{~mm} / \mathrm{min}$.

\section{Conclusions}

1. Finite-element method was used for mathematical modelling of weldability on PVR-Test and computational data were received on distribution of temperature, stresses and strains in different zones of the welded joint.

2. Local deformations, appearing at high temperatures, were computed for a plane sample of nickel alloy of $\mathrm{Ni}-\mathrm{Cr}-\mathrm{Fe}$ alloying system and data were acquired relatively to positive increments of plastic deformations in the range of brittleness temperature interval. It is shown that the rate of plastic deformation for given modelling conditions varies from 0.00119 to $0.00539 \% /{ }^{\circ} \mathrm{C}$. This will determine higher susceptibility to hot crack formation in BTI 2 in this section.

3. The results of numerical prediction of material susceptibility to hot crack formation well agree with the experimental data that allows using the model for evaluation of risks of crack appearance in different zones of the welded joint.

1. Boellinghaus, T., Lippold, J., Cross, C. (2016) Cracking phenomena in welds. Springer.

2. ISO/TR 17641-3:2005: Destructive tests on welds and metallic materials — hot cracking tests for weldments: Arc welding processes. Pt 3: Externally loaded tests.

3. Fink, C., Keil, D., Zinke, M. (2012) Evaluation of hot cracking susceptibility of Ni-based alloys by the PVR-Test. Welding in the World, 56(7/8), 37-43.

4. Vallant, R.,Cerjak, H. The influence of different $\mathrm{Nb} / \mathrm{C}$ ratio in Ni-base weld metals type 70/20 and 70/15 on the hot cracking susceptibility. IIW Doc. II-1535-04.

5. Prokhorov, N.N. (1956) Problem of metal strength in welding during solidification. Svarochn. Proizvodstvo, 6, 5-11.

6. Yushchenko, K.A., Savchenko, V.S., Chervyakov, N.O. et al. (2011) Comparative hot cracking evaluation of welded joints of alloy 690 using filler metals FM 52 and 52 MSS. Welding in the World, 55(9/10), 28-35.

7. Lindgren, L.-E. (2006) Numerical modeling of welding. Computer Methods in Applied Mechanics and Engineering, 195, 6710-6736.

8. Makhnenko, V.I. (1976) Calculation methods for investigation of kinetics of welding stresses and strains. Kiev: Naukova Dumka. 